\title{
The production of salary profiles of ICT professionals: Moving from structured database to big data analytics
}

\author{
Ramachandran Ramasamy \\ Head of Policy, Capability and Research, The National ICT Association of Malaysia (PIKOM), Malaysia \\ Tel.: +6 018595 2922; Fax: +6 018595 2922; E-mail: ramachan@pikom.org.my
}

\begin{abstract}
The national information communications technology (ICT) industry association (popularly known as PIKOM) in collaboration with the largest online job recruitment service provider, namely Jobstreet.com, has been publishing salary profile of ICT professionals in Malaysia annually since 2006. The series has been publishing average salary of ICT professionals by industry, job category, employment size, geographical locations and top paying industry. The online job registration system that Jobstreet.com biannually updates constituted the data source for the statistical activity. The reported data are of high quality as there is an inherent tendency for jobseekers to furnish accurate information in search of new jobs or career advancements. The past series also demonstrated consistency and stability in data trends that official statistics is equally concerned about. Not only private sector, the mainstream policy and planning agencies also have become vivid user of PIKOM data, in particular ICT salary records at three digit occupation and five digit industry levels. Typically such levels of data dissemination are not feasible under national sample surveys. More importantly, the ICT salary data are published as official statistics in the Digital Economy Satellite Account (DESA) system that consolidates all ICT data in the country including private sector initiatives. As next level collaboration, the paper also discusses big data analytics (BDA) targeted at semi-structured and unstructured data that the online job registration system entails.
\end{abstract}

Keywords: Industry collaboration, ICT job salary profile, business intelligence analytics, big data analytics

\section{Introduction}

This paper attempts to depict a practical scenario where data generated by the private sector can be sourced or tapped upon for the interest and use by both the business community as well as government officials. Typically, mainstream public policy institutions and planning agencies rely upon official statistics for formulating programmes and development activities. However, in the absence of data government agencies resort to private sector data provided the data is of acceptable quality and more so, it is produced by credible institution that exercise statistical integrity, proficiency and competency. Before proceed to understand the role of private sector in the official statistical collation, understanding the fundamental tenets of official statistics especially as per definition provided by the Interna- tional Statistical Institute (ISI)/International Association of Official Statistics (IAOS) and United Nations Statistical Division (UNSD) is imperative. As stipulated in the Fundamental Principles of Official Statistics by the United Nations Statistical Division (UNSD) "Official statistics, by definition, are produced by government agencies and can inform debate and decision making both by governments and by the wider community [19]41]. Objective, reliable and accessible official statistics give people and organisations, nationally and internationally, confidence in the integrity of government and public decision making on the economic, social and environmental situation within a country. They should therefore meet the needs of a range of users and be made widely available. In other words, "produced by government agencies" presumably relates not only national statistical offices worldwide, but 
also government-linked agencies and ministries that undertake statistical collation activities for public policy needs.

What about the data compiled by private sector especially business and industry associations? They also like the official statistical members are equally concerned about quality of data that they produce from their business operations and administrative records. Can such data be considered as "official statistics"? The question is not so much 'why' but 'why not?' since the private sector can assure conformity to strict professional considerations, scientific principles and professional ethics, on the methods and procedures for the collection, processing, storage and presentation of statistical data that UNSD's Fundamental Principles of Official Statistics pertinently emphasize. Indeed, in the current situation where the world is increasingly becoming connected in real time through Internet and digitization phenomena, and more so with advanced technological capabilities the private sector able generate new sets of data with great ease. Not only private sector, but also the mainstream policy institutions and planning agencies are increasingly turning to such data sources especially when the mainstream official statistical institutions could not cope up with new data demands. Pertinently, this paper elucidates the on-going collaboration between the National Information Communications Technology (ICT) Association (popularly known as PIKOM) and the online job recruitment service providers (namely Jobstreet.com and PayScale.com), relating compilation of salary profile of ICT professionals at lowest level of occupation and industry classifications that are typically not feasible under sample surveys regularly carried out by national statistical agencies.

Besides that, the paper also expounds the possibility of expanding the on-going effort to the next level by leveraging the fast growing BDA opportunities that provide analytical capability entailing not only matrix data but also semi-structured and unstructured data in real time. In the business world, the growing notion is that as the future unfolds, more business decisions will be supported by the facts that only analytics can provide; as such fewer business decisions will be made on the basis of instinct and guesswork in the near future [2533]. Reckoning the growing importance and relevance of analytics many business organizations have geared up to take advantage of whatever opportunities that big data analytics (BDA) may offer. In fact, BDA phenomena are growing an astounding rate. This new phenomena helps organisations by not only collecting, organising and analysing patterns and trends residing in online and in real time large data sets, but also directs in discovering the data that are most important to the business and future business decisions [14]. Indeed, BDA processes are pervading into business organisations of all sizes and types at an unprecedented rate in the history of analytics [9], though participation of bigger organizations are currently more pronounced at the moment. Government organisations including official statistical systems are also no exception to BDA phenomena, notions and trends. Specifically, Big Data and Official Statistics initiatives by Eurostat and Department of Statistics of Hong Kong, Official Statistics Australian Bureau of Statistics (ABS) Big Data Flagship and Irish Centre for High-End Computing (ICHEC) are already experimenting data residing in web, e-commerce and sensors using BDA approach [40 42].

\section{On-going effort between PIKOM and online job service providers}

Since 2006 the National ICT Association of Malaysia (popularly known as PIKOM) in collaboration with the largest online job service provider, namely Jobstreet.com has been publishing salary profile of ICT professionals in Malaysia annually. PIKOM is the association representing the information and communications technology (ICT) industry in Malaysia. Its membership currently stands at 1000+ comprising companies involved in a whole spectrum of ICT products and services, which commands $80 \%$ of the total ICT trade in Malaysia. Formed in August 1986, PIKOM is ambitioned to creating an environment that is conducive to healthy growth of the ICT industry in Malaysia. Specifically, PIKOM promotes development of resources, professional skills and programs in the local ICT industry; provides a platform for ICT players and users to meet, network, learn and share ideas in order to bring the industry to the next level; represents the local ICT industry to the Government and private sector both local and overseas; fosters high standards of conduct, service and performance throughout the ICT industry; and expands local ICT services to the region and overseas. Being the voice of ICT industry PIKOM also actively plays the role of policy advocacy and intervention by participating in policy dialogues with Economic Planning Unit (EPU) of Prime Minister's Department; annual budget dialogues with the Ministry of Finance (MOF); indus- 
try dialogues with Ministry of International Trade and Industry (MITI); and trade dialogues with Malaysian Royal Customs and Excise Department, among many other representations. In support of advocacy activities PIKOM also undertakes policy, business and market development research of top-notch quality that has gained attention of mainstream. Among many others, one such area is the compilation of salary profile of ICT professionals that highlighted earlier. JobStreet.com is a job portal founded in Malaysia in 1997. It is now Southeast Asia's largest online employment company [15]. It became a public listed entity in 2004 when parent company JobStreet Corporation Berhad was listed on the MESDAQ Market of Bursa Malaysia Securities.

PIKOM does not own any salary profile database of ICT professionals. Moreover, for reasons of security and confidentially, PIKOM have no access to the online job registration system that Jobstreet.com biannually updates and maintains. Nonetheless, PIKOM has successfully instituted an annual arrangement with Jobstreet.com to provide the latest salary reports of ICT professionals. Data is furnished for 22 industries by job category, of which six are pertaining to ICT segments namely call centre/IT enabled services, computer/IT hardware, computer/IT software, telecommunications, semi-conductor and wafer fabrications, and electrical and electronics [32]. The job category entails fresh graduates, junior ICT executive with fewer than 4 years of experience, senior ICT executive with 5 years and above of working experience, middle ICT manager and senior ICT manager.

For each industry and job category, Jobstreet.com provides monthly salary of ICT professionals at quartile points $\left(25^{\text {th }}, 50^{\text {th }}\right.$ and $75^{\text {th }}$ percentile points), which in turn converted into weighted mean using the following procedure:

$$
\begin{aligned}
& \text { Weighted average salary, } X=\left(0.25^{*} Q_{1}\right) \\
& \quad+\left(0.50^{*} M\right)+\left(0.25^{*} Q_{3}\right), \\
& \text { where } Q 1 \text { and } Q 3 \text { represents first and third quartile } \\
& \text { points and } M \text { is the median salary }
\end{aligned}
$$

Apart from salary information, Jobstreet.com provides survey based economic perceptions of job seekers and industry players as well as Jobstreet.com Employee Confidence Index (JECI) for gauging job sentiment monthly. JECI ranges from zero indicating tough job market situation and 100 indicating comfortable job market where people able to secure a good job easily.

Since 2012, the coverage further expanded to provide median salary by type of ICT job functions, em- ployment size, years of working experience, geographical location and gender. These data are extracted from PayScale.com web publishing. PayScale.com is also an online job service provider, operating at global level by covering 87 countries. For each variable category, PayScale.com provides salary data at 10\%, 50\%, $70 \%$ and $90 \%$ percentile points. However, PIKOM only extracts and publishes median salary data at $50 \%$ percentile. The number of respondents covered differs among variable categories and statistically large enough for adequate representation.

For regional comparisons the median salary records are converted into the scaling numbers by assuming a scaling factor of one for Malaysia. The average salary value for each country is obtained by averaging across three variables namely IT skills, company size and years of working experience. Two types of benchmarks are published, one by taking into consideration of purchasing power parity (PPP) adjusted and the other is non-PPP adjusted, popularly known as Atlas criterion. PayScale.com publishes Atlas criterion data but all measures are tallied in US. Atlas criterion median salary records ( $\left.\mathrm{X}_{\text {atlas criterion }}\right)$ are converted to PPP adjusted median salary $\left(\mathrm{X}_{\text {ppp adjusted }}\right)$ using the gross domestic product (GDP) figures published annually by World Bank data, as follows:

$$
\begin{aligned}
& \mathrm{X}_{\text {ppp adjusted }}=\mathrm{X}_{\text {atlas criterion }} * \\
& \quad\left(\mathrm{GDP}_{\text {ppp adjusted }} / \mathrm{GDP}_{\text {atlas criterion }}\right)
\end{aligned}
$$

PPP is considered a more refined measure as it provides a more meaningful comparison by taking into account of inflation rates and foreign exchange rates. Indeed, technically speaking ambitious job seekers should use PPP adjusted scaling numbers when searching for overseas jobs. Selected Asian and English speaking countries, where the Malaysian ICT professionals have higher tendency to head for in search of better employment opportunities and career advancements are considered. The Asian countries include Singapore, Indonesia, Thailand, Philippines, Vietnam, Hong Kong, India and China and English speaking destinations include USA, Australia, United Kingdom, Canada and New Zealand. Moreover, these countries have strong and long established diplomatic, trade and cultural ties with Malaysia. Being English is a popular lingua franca among Malaysian businesses especially among the private sector and thus, there has been always a natural attraction for Malaysians to do more businesses with such English speaking countries, despite distance in some cases. Indeed, these destinations are no exception to ICT professionals as well, especially software developers and networking engineers who are in demand at all times globally. 


\section{Data quality assessment}

Data quality assessment is a precondition for informing the users about the possible uses of the data [12]. Recognizing the imperative, this section used the framework outlined in the Handbook on Data Quality Assessment Methods and Tools of European Commission on assessing data quality, as follows.

\subsection{Relevance}

Since its inception in 2006 the scope and coverage of salary profile of ICT professionals have expanded in stages and as such, in its latest series published average salary by industry, job category, ICT segments, ICT job functions, employment size, years of working experience, top-paying industry, geographical location, gender, regional countries and major cities around the globe. The report also provides job confidence index that gauges health of the ICT job market, ICT and economic outlook and economic perceptions of job seekers and employees. Initially, the industry players and human resource practitioners were the key data users, particularly being used in job recruitment exercises and salary adjustment decision making processes. But, over the years the ICT salary records attracted the attention of public policy formulators, programme planners, project implementers and development practitioners in the mainstream. Specifically, the mainstream users require ICT salary records at three digit occupation and five digit industry levels, which such levels of data dissemination are not feasible under national sample surveys that national statistical office undertakes regularly namely Malaysian Labour Force Survey, National Household Income Survey and National Household Expenditure Survey.

\subsection{Accuracy}

Essentially the salary records of ICT professionals discussed in this paper sourced from online job registration administrative records of Jobstreet.com and PayScale.com. Job seekers regularly update their records especially when the online job service providers prompt them to do so, at least once a year. The quality of data is very much depends upon the attitude of job seekers who have the liberty and the options to furnish the correct information or not. It is inherently assumed that the job seekers provide accurate information, which is critical for searching new jobs or pursuing career advancements; otherwise, their chances may come under jeopardy.

\subsection{Process quality}

Job street.com has instituted sound methodology, appropriate statistical procedures and cost effective means in extracting data from the online job registration system [18]. Besides that data transcriptions into aggregated form and reporting activities are highly computerized, thus inherently errors arising from data processing activities are mitigated.

\subsection{Validity}

As highlighter earlier the online job registrations systems are typically encompass large populations that are critical for providing stability and consistency in the data. At of end of 2014, Jobstreet.com serves about 230,000 corporate customers and 13 million jobseekers covering the employment markets in Malaysia, Singapore, Philippines, Indonesia, India, Japan, Thailand and Vietnam; a decade ago the numbers were 15000 employers and 1.85 million job seekers only, respectively. It provides recruitment services for all categories of jobseekers, from fresh entrants to labour force after graduation to senior level positions. Of the overall total in 2013, IT or the computer segment alone constituted $8 \%$ of its database. Of which, $84 \%$ have post-secondary qualifications that is, diploma, degree, professional certifications and post graduate qualifications. By job category, $82 \%$ of them were job seekers in executive and higher level consisting of fresh graduates, junior, senior, managerial and senior managerial category. Similarly, PayScale.com being a global online job service provider maintains 40 million salary profiles, 3000 customers, 3,500 industries and 15,000 jobs. Salary compilation is confined to 11 countries, of which Malaysia is one of their key customers. By virtue of corporate standing and branding, succinctly put PIKOM, Jobstreet.com and PayScale.com maintain high credibility in whatever endeavour that they pursue. Indeed, in pursuant of this statistical activity PIKOM and Jobstreet.com have successfully developed mutual trust and confidence over the years and currently poising to move up in their collaboration to next level.

\subsection{Comparability and coherence}

The information and communications sector as per Malaysian Standard Industrial Classification 2008 (MSIC 2008), which is based on International Standard Industrial Classifications (ISIC Revision 4) of the 
Table 1

Salary profile of ICT professionals, national household income growth and consumer price index 2006-2013

\begin{tabular}{|c|c|c|c|c|c|c|c|c|c|}
\hline \multirow[t]{3}{*}{ Year } & \multirow{2}{*}{\multicolumn{2}{|c|}{$\begin{array}{c}\text { Jobstreet.com } \\
\text { Average salary of } \\
\text { ICT professionals } \\
\text { (Ringgit Malaysia) }\end{array}$}} & \multicolumn{6}{|c|}{ Department of statistics malaysia (DOSM) } & \multirow{3}{*}{$\begin{array}{l}\text { Value added } \\
\text { ICT services } \\
\text { (RM billion) }\end{array}$} \\
\hline & & & \multicolumn{2}{|c|}{$\begin{array}{c}\text { Total annual salaries and } \\
\text { wages in telecommunications } \\
\text { and computer sector }\left(R M^{\prime} O 00\right)\end{array}$} & \multicolumn{2}{|c|}{$\begin{array}{l}\text { Average household } \\
\text { income } \\
\text { (Ringgit Malaysia) }\end{array}$} & \multirow{2}{*}{ 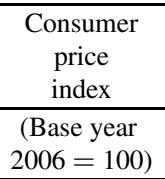 } & \multirow{2}{*}{$\begin{array}{c}\text { Gross domestic } \\
\text { product growth } \\
\text { rate } \\
\%\end{array}$} & \\
\hline & $\begin{array}{c}\text { Inflation } \\
\text { unadjusted }\end{array}$ & $\begin{array}{l}\text { Inflation } \\
\text { adjusted }\end{array}$ & $\begin{array}{c}\text { Inflation } \\
\text { unadjusted }\end{array}$ & $\begin{array}{c}\text { Inflation } \\
\text { adjusted }\end{array}$ & $\begin{array}{c}\text { Inflation } \\
\text { unadjusted }\end{array}$ & $\begin{array}{c}\text { Inflation } \\
\text { adjusted }\end{array}$ & & & \\
\hline 2006 & 4,184 & 4,184 & $3,755,858$ & $3,755,858$ & 3,576 & 3,576 & 100.0 & 5.6 & 23.86 \\
\hline 2007 & 4,443 & 4,355 & $4,197,778$ & $4,114,378$ & 3,686 & 3,613 & 102.0 & 6.3 & 25.04 \\
\hline 2008 & 4,807 & 4,470 & $4,735,405$ & $4,403,842$ & 3,854 & 3,584 & 107.5 & 4.8 & 30.09 \\
\hline 2009 & 5,200 & 4,806 & $4,758,128$ & $4,397,342$ & 4,025 & 3,720 & 108.2 & -1.5 & 32.00 \\
\hline 2010 & 5,714 & 5,193 & $5,140,650$ & $4,671,678$ & 4,352 & 3,955 & 110.0 & 7.4 & 42.09 \\
\hline 2011 & 6,165 & 5,429 & $5,623,308$ & $4,952,245$ & 4,657 & 4,101 & 113.6 & 5.1 & 45.26 \\
\hline 2012 & 6,673 & 5,781 & $6,321,740$ & $5,476,228$ & 5,000 & 4,331 & 115.4 & 5.6 & 52.4 \\
\hline 2013 & 7,152 & 6,068 & $7,088,832$ & $6,014,126$ & 5,450 & 4,624 & 117.9 & 4.7 & 59.84 \\
\hline $\begin{array}{c}\text { AAGR: } \\
\text { 2006-2013 }\end{array}$ & $8.0 \%$ & $5.6 \%$ & $9.5 \%$ & $7.0 \%$ & $6.7 \%$ & $3.7 \%$ & $2.4 \%$ & $4.8 \%$ & $14.0 \%$ \\
\hline $\begin{array}{l}\text { Coefficient of } \\
\text { Variation }(\mathrm{CV})\end{array}$ & $19 \%$ & $14 \%$ & $21 \%$ & $16 \%$ & $14 \%$ & $10 \%$ & $6 \%$ & & $34 \%$ \\
\hline
\end{tabular}

Source: ICT Job Market Outlook 2014, PIKOM; various publications of Department of Statistics (DOSM).

United Nations Statistical Division (UNSD) entails six industries. They are publishing activities, motion picture, video, television, sound and music productions, programming and broadcasting, information activities, computer programming, consulting and related activities and telecommunications. MSIC 2000 that was in force prior to MSIC 2008 entailed only telecommunications and computer services sectors, for which data on total salaries and wages were available for the period 2008-2013 that the exercise focuses. For assessing coherence, consistency and stability over time series the average monthly salary of ICT professionals that were collated from Jobstreet.com records are compared against the total salaries and wages paid only in the telecommunications and computer services sectors, as published officially by the Department of Statistics Malaysia (DOSM). Strictly speaking, data from these two sources are not comparable as they differ in terms of statistical concepts, measurement tools, procedures and approaches and methodological standards. Specifically, Jobstreet.com data are based on 22 industries entailing not only core ICT segments but also user industries such as banking, insurance, education et cetera, in comparison DOSM data pertains to only supply side or producer of ICT services. In terms of employment the DOSM data covers working proprietors, active business partners, unpaid family workers, full-time employees and part-time employees, whereas Jobstreet.com data strictly confined to only ICT professionals. The other major difference is that salaries and wages in the DOSM data refers to gross emoluments paid to employees during the reference year inclusive of salaries, wages, commission, overtime pay, dismissal pay and allowances as well as employee provident and insurance deductions. In comparison, Jobstreet.com data strictly reports monthly salary, excluding perks and benefits. However, it is conjectured that in the information and communications sector bulk of the employees are ICT professionals, which enable some levels of meaningful comparability. As shown in Table 1, as per Jobstreet.com records average monthly salary of ICT professionals grew at an average growth rate of (AAGR) of $8.0 \%$, which interestingly did not differ very much from overall salaries and wages growth rate of $9.5 \%$ per annum as per DOSM published records for the period 2006-2013. After taking into consideration of inflation, the growth rates differed only marginally, $5.6 \%$ under Jobstreet.com and $7.0 \%$ under DOSM; refer to Table 1.

\subsection{Consistency and stability}

Private sector data are usually market or business driven and at times data quality is questionable especially its consistency and stability over time. So far the series has compiled eight data points since 2006. Coefficient of variation (CV), defined as standard deviation per unit statistical mean is used to assess the data consistency especially stability of the time series distribution [27]. Except for Global Financial Crises in 2009 the economy of Malaysia registered a steady positive growth, registering an average growth rate of $4.8 \%$ per annum during the period 2006-2013 as shown in Table 1. In tandem, the ICT Services sector that employs bulk of the ICT professionals also grew steadily at an average growth rate of $14.0 \%$ per annum by registering 
Table 2

Average monthly gross salary of ICT professionals by job category: 2010-2013

\begin{tabular}{|c|c|c|c|c|c|}
\hline Year & $\begin{array}{l}\text { Fresh graduates } \\
\text { (Entry level) }\end{array}$ & $\begin{array}{c}\text { Junior executive: } \\
\text { (1-4 years working } \\
\text { experience) }\end{array}$ & $\begin{array}{c}\text { Senior executive: } \\
(\geqslant 5 \text { years working } \\
\text { experience })\end{array}$ & $\begin{array}{l}\text { Middle management: } \\
\text { (Manager) }\end{array}$ & $\begin{array}{l}\text { Senior management: } \\
\text { (Senior manager) }\end{array}$ \\
\hline \multicolumn{6}{|l|}{ Ringgit Malaysia (RM) } \\
\hline 2011 & 2,238 & 3,151 & 5,039 & 7,837 & 12,166 \\
\hline 2012 & 2,343 & 3,205 & 5,344 & 8,381 & 13,446 \\
\hline 2013 & 2,451 & 3,439 & 5,744 & 8,986 & 14,738 \\
\hline $\begin{array}{l}\text { Percentage change }(\%) \text { : } \\
2012-2013\end{array}$ & 4.6 & 7.3 & 7.5 & 7.2 & 9.6 \\
\hline $\begin{array}{l}\text { AAGR (\%): } \\
2011-2013\end{array}$ & 4.7 & 4.5 & 6.8 & 7.1 & 10.1 \\
\hline \multicolumn{6}{|c|}{ Comparison against average monthly salary of fresh graduates } \\
\hline 2011 & 1.00 & 1.41 & 2.25 & 3.50 & 5.44 \\
\hline 2012 & 1.00 & 1.37 & 2.28 & 3.58 & 5.74 \\
\hline 2013 & 1.00 & 1.40 & 2.34 & 3.67 & 6.01 \\
\hline
\end{tabular}

Source: ICT Job Market Outlook 2014, PIKOM.

value added services worth RM23.9 billion in 2006 to RM59.8 billion in 2013; refer to Table 1. Under such stable economic environment there is no unduly variation observed within the data series itself and also consistency between Jobstreet.com and DOSM datasets as reflected in the CV measurements; in particular, 19\% for Jobstreet.com and $21 \%$ for DOSM data and with inflation adjusted the CV measures were $14 \%$ and $16 \%$, respectively.

\subsection{User perceptions and satisfaction}

As acknowledged, users will in many cases perceive product quality differently than the product or services producers. Some of the quality components are difficult to assess for the users unless the users have some basic knowledge of statistical methodology. Similarly, it will usually not easy for non-expert users who lack statistical competency to define their quality requirements. In such situations user acceptance is used as the key criterion in gauging user perceptions and satisfactions. Unexpectedly, the mainstream public policy and planning institutions in Malaysia have shown great interest not only in the ICT salary data published by PIKOM but also other data like estimation of ICT trends and statistical forecasts presented in industry thought leadership articles, despite being private sector driven initiatives. Very often mainstream agencies engage PIKOM in policy dialogues, budget dialogues and soliciting industry inputs in the preparation of development plans and industry standards and trade promotion activities. Indeed, PIKOM is the only private sector industry association has been accorded a membership status in Digital Economy Satellite Account (DESA) system that aimed at consolidating all ICT data in the country. DESA was formed in 2011 under the headship of Ministry of Finance (MOF). Among many other agencies, DOSM and Economic Planning Unit (EPU) of Prime Minister's Department are also members of DESA, where they not only supply ICT data collated by them but also as key producers and users of official data endorse ICT data that are compiled by other agencies, including PIKOM.

\section{Data usage: Business and policy perspectives}

Since 2006, without any disruption PIKOM has been successfully publishing the salary profile of ICT professional data in the ICT Job Market publication series. Initial objective of this statistical endeavour is to meet the needs of PIKOM members who can be surmised broadly under four categories namely wholesalers and retailers of ICT products, producers of ICT Services, ICT user community especially the chief information officer (CIO) and chief technology officer (CTO) and Outsourcing Sector members. Over the years human resource practitioners, man hunters and job recruiters and strategic planners in the private sectors also have become regular users of PIKOM's salary report. Upon reckoning the quality of data published, the mainstream policy and planning agencies as well as development practitioners not only have become users of PIKOM's publications but also have begun to engage the ICT industry association as strategic partners in public policy and programme formulation exercises. The salary report furnishes wide range of information. However, the key ones that drew attention of mainstream agencies include ICT salary growth trends; widening disparity across ICT job category; rise of 
Table 3

Monthly median salary of ICT professionals by job function

\begin{tabular}{|c|c|c|c|c|}
\hline Job functions & $\begin{array}{c}\text { Number of } \\
\text { respondents (in 2013) }\end{array}$ & $\begin{array}{c}2013 \\
\text { (Ringgit Malaysia) } \\
\end{array}$ & $\begin{array}{c}2012 \\
\text { (Ringgit Malaysia) } \\
\end{array}$ & $\%$ Change \\
\hline $\begin{array}{l}\text { Information Technology, Project Manager (Java, HTML, } \\
\text { SQL, Microsoft Certified Professionals) }\end{array}$ & 586 & 8,947 & 7,165 & 24.5 \\
\hline SAP Consultants & 595 & 7,817 & 7,642 & 2.2 \\
\hline $\begin{array}{l}\text { Senior Database/System Administrators (Microsoft and } \\
\text { Cisco Certified) }\end{array}$ & 76 & 7,580 & 6,867 & 10.4 \\
\hline $\begin{array}{l}\text { Information Technology Consultants (Java, HTML, } \\
\text { MCP) }\end{array}$ & 255 & 6,967 & 6,920 & 0.7 \\
\hline $\begin{array}{l}\text { Senior Software Engineer (Java, HTML, SQL, Microsoft } \\
\text { Certified Professionals) }\end{array}$ & 362 & 6,956 & 5,973 & 16.5 \\
\hline $\begin{array}{l}\text { Database/System Administrators/SQL (Microsoft and } \\
\text { Cisco Certified) }\end{array}$ & 53 & 5,044 & 4,327 & 16.6 \\
\hline Programmer/System Analyst (Java, HTML, SQL) & 124 & 4,099 & 3,432 & 19.4 \\
\hline Software Developer/Programmer (Java, HTML, SQL) & 226 & 4,034 & 3,778 & 6.8 \\
\hline $\begin{array}{l}\text { Software Engineer (Java, HTML, SQL, Microsoft Certi- } \\
\text { fied Professionals) }\end{array}$ & 704 & 3,949 & 2,997 & 31.8 \\
\hline AutoCAD: Civil Engineering & 667 & 3,459 & 3,419 & 1.2 \\
\hline Web designer, HTML & 73 & 3,173 & 2,773 & 14.4 \\
\hline
\end{tabular}

Source: ICT Job Market Outlook 2014, PIKOM; PayScale.com.

knowledge workers by technical and managerial category; and talent retention and migration regionally. For illustration purposes, this paper highlights the role of salary report in addressing the public policy concerns plaguing the ICT industry, besides business perspective usage.

\subsection{ICT salary growth trends}

The Table 1 shows the average monthly salary of ICT professionals in Malaysia. At overall level monthly salary trend of ICT professionals grew at an annual average growth rate (AAGR) of $8.0 \%$ during the period 2006-2013, that is increased from RM4,184 to RM7,152. However, with inflation adjusted the average monthly salary of ICT professionals grew only at $5.6 \%$, from RM4,184 to RM6, 068 during this period. In comparison, average monthly household income grew at 6.7\%, that is from RM3,576 in 2006 to RM5,450 in 2013; however, with inflation adjusted AAGR stood at $3.7 \%$. Table 1 shows the consumer price index (CPI) which grew at AAGR of $2.4 \%$ during the period. Succinctly put, on the overall the average income growth of ICT professionals in Malaysia has edged over inflation growth rate, and also in real income terms this professional category have been earning higher salary than a typical household in the country.

\subsection{Disparity across ICT job category}

Despite overall growth in average salary, as shown in Table 2 the gap among ICT job category has been widening as observed during the period (2011-2013). Specifically, the AAGR of monthly salary of ICT fresh graduates and junior executives grew only at $4.7 \%$ and $4.5 \%$ respectively, which much lower in comparison to $6.8 \%$ for senior executives, $7.1 \%$ for middle managers and $10.1 \%$ for senior managers. Such widening gap is considered not healthy from public policy perspective, which has inherent development objective to narrow socio-economic gaps through redistribution of wealth strategies. Industry association like PIKOM also viewed this widening disparity seriously, indeed has signalled the industry players that appropriate measures are needed to reduce the gap. Otherwise, the industry will continue to face rampant job hopping problem among lower category ICT professionals in search of better opportunities and career advancement. In the job tight environment in Malaysia where the unemployment rate has been low over the past two decades, lingering around at 3\%, job hopping pose instability to the industry growth. For the employee job hopping may provide wide exposure and experience across many industries and different size companies as well as provide greater access to information and resourceful networks. But from the employers' and investors' perspectives, workforce disruptions can cost businesses millions in lost productivity. It is always a costly and time consuming process for employers recruiting, courting, hiring and ramping up new employee in an attempt to provide stable employment, instil staff loyalty and long term retention. From policy perspective widening salary gap widens the societal disparity that public policy always attempts to redress to avert unduly dissatisfaction citizens. 


\subsection{Rise of knowledge workers by technical and managerial category}

The average median salary earned by key ICT professionals is shown in Table 3. On assuring the data quality, the Table 3 also provides number of reporting individuals by job function, as reported by PayScale.com. The number indicates that reporting is based on adequately large number of observations that statistical compilations are concerned with. It can be seen from this table that ICT professionals in the management category, whether they are Java, HTML, SQL or MCP certified, netted the highest earnings compared to other ICT job functions. IT Project Managers could net a median monthly salary as high as RM 8,947 in 2013, which is $24.9 \%$ higher compared to RM 7,165 in 2012. Being a highly specialized job, the average median salary earned by SAP Consultants in 2013 was RM7,817, which marginally increased by $2 \%$ from RM7,647 in 2012; however, experienced ones can net double this amount. Those in the technical line especially the Software Engineers, Senior Software Engineers and Programmer and System Analysts too registered significant growth in median salary by $31.8 \%$, $19.4 \%$ and $16.5 \%$ respectively. From both business and public policy perspective the salary records by job functions seem to indicate that non-technical type or managerial functions are paid better than their counterparts in technical fields. Indeed, the findings contravene the Government aspiration of increasing the contemporary knowledge workers pool. Knowledge workers especially those specialize in technology driven creativity and innovation are considered critical for ushering the nation into innovation based economy. The Government also has made a clarion call to accord due employment status and recognition by offering better remunerations, perks and accreditations as well as motivations.

\subsection{Supply and demand for competent ICT workforce}

According to PIKOM's past findings, only $10 \%$ of the new entrants to the workforce are directly employable, while others need to be trained before placing in proper routines [32]. This is not only industry concern but also policy, education and human resource institutions responsible for producing employable and competent workforce. Companies especially the smaller ones are not willing to mobilize their scarce resources in training or coaching or mentoring activities in fear of rampant job hopping behaviours among new recruits.
According to the ICT salary report, the big companies having employment size more than 2000 on an average pay 1.78 times higher than small companies having less than 10 employees [32]. When the data was investigated in terms of geographical location the average salary of ICT employees in highly urbanized areas like in Kuala Lumpur or Putra Jaya tend to earn 1.75 times higher than in Kuching or Ipoh where investments and business activities are considered lower. As such, there is always a strong tendency among new entrants in job market to move to better paying companies or locations once they have acquired adequate experiences and exposures. As shown in Table, 1 the average salary of fresh graduates grew only at AAGR of $4.7 \%$ compared to $10.1 \%$ registered at senior management level, reflecting poorly on the ICT job market outlook in the country and more so, brings about negative implications on the supply of right ICT talents in adequate number.

In the Malaysian experience, the ICT enrolment in higher learning institutions including both public and private have almost halved from 96,090 in 2002 to 49,731 in 2012 [32 43]. When the Government launched MSC Malaysia (previously known as Multimedia Super Corridor) programme in 1994 as the key enabler and driver of migrating from agro-industrial base to knowledge based economy (KBE) the demand for ICT graduates shot up significantly [43]. In tandem, liberalization of higher education sectors through Education Act 1995 enactment fuelled the growth of private education system and expansion of ICT courses in the country (ICT Human Capital Development Framework 2012). Beginning with dawn of new millennium ICT enrolments have begun to register sharp decline for various reasons. First, disillusionment for parents and prospective students arose from infamous "dotcom bubble burst" global phenomena in 2000 that led to closure of many ICT start-up companies. Second, lack of professional recognition and prestige for ICT professionals in comparison to perceived glamour accorded to medicine, engineering, architecture, legal and accountancy fields. Third, Gartner study revealed that globally declining interest in ICT profession among younger generations due to high technological demands and long and tiring working hours. Fourth, slow growth in average salary for the ICT fresh graduates adds woes to the existing human capital supply problems and challenges in adequate number and quality that the industry has been plagued with. Last and not least, all these factors in one way or other have gravitated prospective students to pursue other 
Table 4

Benchmarking ICT salary scaling numbers by countries against Malaysia by atlas and PPP criteria, 2013

\begin{tabular}{lcclrl}
\hline Country & Atlas & PPP & Country & Atlas & PPP \\
\hline Malaysia & 1.00 & 1.00 & United States & 3.13 & 1.90 \\
Viet Nam & 1.50 & 2.19 & New Zealand & 2.77 & 1.64 \\
Hong Kong & 2.46 & 2.12 & Australia & 3.46 & 1.52 \\
China & 2.03 & 1.93 & Canada & 2.87 & 1.44 \\
Singapore & 2.28 & 1.75 & United Kingdom & 2.40 & 1.40 \\
Thailand & 1.43 & 1.54 & & & \\
India & 0.48 & 0.72 & & & \\
Indonesia & 0.78 & 0.65 & & & \\
Philippines & 0.44 & 0.46 & & & \\
\hline
\end{tabular}

Source: PIKOM, ICT Job Market Outlook 2014.

fast emerging courses especially in health related studies, which in recent years the Malaysian Government also have been vehemently advocating on provision of quality health services for all.

\subsection{ICT talents retention and migration regionally}

The other useful data gleaned from the exercise was regional benchmarking salary data, which compared the average ICT salary of Malaysian ICT professionals with their counter parts regionally and globally. This piece of information is increasingly becoming important for both industry players who are concerned about employee retention strategy and policy planners who are concerned about talent pool depletion arising from job migration across borders. Specifically, the low remuneration always constituted as push factor for professionals in search of better career opportunities and advancements not only in the region also across distant lands especially those friendly nations that have long diplomatic and trade ties. As reflected in Table 4 that provides regional benchmarking by Atlas (nominal figures) and Purchasing Power Parity (PPP) adjusted data for the year 2013 has revealed that of all countries studied except Indonesia, India and Philippines have emerged as an attractive destination for competent Malaysian ICT workforce and fresh graduates. The distant lands that have become attractive destinations for Malaysians are mostly English speaking countries, in particular United States of America, United Kingdom, Canada, Australia and New Zealand. Since English has been a popular lingua franca among Malaysian businesses especially among the private sector and there has been always a natural attraction for Malaysians to do more businesses with such English-speaking countries. These destinations are no exceptions for ICT Professionals as well, especially software developers and networking engi- neers who are in demand at all times globally including Malaysia.

Recognizing the talent retention and migration challenges, in January 2011 Malaysian Government established the TalentCorp institution to address the talent gaps, issues and challenges in the country [32]. Since its inception, TalentCorp has implemented three major public policy thrusts. First, is to optimize Malaysian talents through initiatives such as providing career awareness and to work transition and building career guidance, enhancing school platforms on optimise talents. Second, is to attract and facilitate the global trend through programmes such as outreaching to Malaysians abroad, facilitating returning talents and enhancing expatriate facilitation. Third, is building networks of top talent via building networks of future leaders, developing diaspora networking platforms and engaging the expatriate community.

\section{Moving from structured database analytics to big data analytics (BDA)}

The official statistical community, who have been dealing with a diversity of data sources for decades, are incrementally exploring whether to embrace big data sources in the regular production of official statistics [40]. Succinctly put, the principal considerations that warrant due attention are relevance, validity of using the source especially those originate from private sectors, methodological and analytics procedures and inferences as well as business benefit [40]. Despite challenges, the official statisticians are increasingly acknowledging big data sources have the potential to facilitate the linkage between economic statistics and the people that they are about, improving quality and granularity of existing data and availability of new data that cannot be collected through traditional means [42]. Like the official statistical communities, the ICT industry association and Jobstreet.com are at a crossroads to move up to the next level collaboration, expanding the on-going structured database analytics experience to incorporate BDA approach. PIKOM itself has no direct BDA implementation experience yet however, but the industry association has members with such technical capabilities. Before embarking into any hands-on BDA project it is imperative to have adequate understanding on features and characteristics of these new phenomena. As such, this paper expounds the BDA migratory and conceptual frameworks that possibly provide requisite basis for evaluating the on-going ICT 
salary compilation exercise, in particular the gaps and challenges that warrant due attention in moving to next stage of analytics.

\subsection{Big data analytics (BDA) migratory framework}

As data history cites, big data is not a new phenomenon. It started seventy years ago when first attempts were made to quantify the growth rate in the volume of data [23] or what has popularly been known as the "information explosion" (a term first used in 1941, according to the Oxford English Dictionary), before current buzz around big data emerged. Sixties saw emergence of data support system (DSS) by IBM, which by late 80's evolved into online analytic processing (OLAP) applications. Indeed, OLAP marked the beginning of business intelligence analytics (BIA) models ingrained with fact-based decision making and planning processes [33]. The legacy BIA models essentially confine data processing activities pertaining to organizational operations and processes that are driven by Enterprise Resource Planning (ERP), Customer Relationship Manager (CRM) and Supply Chain Management (SCM) types of systems [1]. With the advent of Internet technology followed by intense virtual digitization processes new types of big and real-time data have begun to flood business environment [3438]. Consequently, unprecedented advancements in data recording and storage technology the traditional BIA systems are compelled to adopt BDA systems. The anticipated changes in the process dimensions and framework include integration of various departmental data within organization; expansion of new data sources through linking to external databases; new technology adoption especially open source culture; changing roles, systems, structures, functionality, cultures and practices in work environment and orientating to customer aspirations, expectations and experiences and responsive to businesses and employee motivations [2]

BIA and BDA systems have common objectives of culling out actionable insights and business intelligence from the data [9]14|25]. However, as highlighted in Fig. 1, there are some distinct characteristics differences if one were to look at how data supported systems of yester years have evolved into BDA of today especially in comparison against BIA. First, BIA confined to structured back-office systems data, in comparison BDA explores, semi-structured and unstructured data sourced from within and outside organizations, besides binary database. Specifically, newer sources include unstructured text from comments and social media streams and semi-structured data from log files and click streams, besides the rectangular array structured traditional databases [3 10 22]. Web based postings, blog spots, You Tube videos, Facebook posts, sensors of various types, call centres, credit card and online payment transactions and store inventories have emerged as key sources on big data. Second, the legacy BIA is technology centric, demands heavy IT involvement like usage of Structured Query Language (SQL) for querying [9], whereas BDA deploys user-friendly interfaces. Third, BDA processes have gone beyond the realms of typical numerical based statistical analysis by encompassing text analytics, context analytics, speech analytics, predictive analytics, prescriptive analytics and embedded analytics (BDA) [3]. Fourth, BIA generates reports and dashboard visualizations for top management review to facilitate top-down driven actions only, while BDA targets customers and employees at all levels and promulgates flow of constructive criticisms and feedback that can improve process, quality and innovation [14]. Fifth, BDA deploys open source solutions like Apache Hadoop, NoSQL, R and Google Analytics that drive down cost significantly in comparison to costly proprietary software used in BIA models [5]. Sixth, being business inclined BDA budgeting requirements are moving away from IT to business team. As such, organizations are reinventing themselves by defining BDA as an integral part of seamless workflows across organizations. Ease of use features and characteristics enables effective data usage and institutionalization of actionable insights at all levels of operations and planning processes. Surmising the whole phenomena, IBM has succinctly differentiated and qualified the upheavals that physical size of the organization or the data set is irrelevant in defining a "big data"; rather as "any data set that cannot be managed by traditional processes or tools" [22].

\subsection{Big data evaluation framework}

Business organizations are at various stages of development [28]. Some organizations plan and carry out business operations by intuition and guesswork as they fear over analysis can paralyse their business performance. Some organizations use only basic data supported system that can generate essential business numbers and help to improve day to day business operations efficiently. Some matured organizations are not only pursuing performance efficiency but also business effectiveness by exploring new frontiers in research 


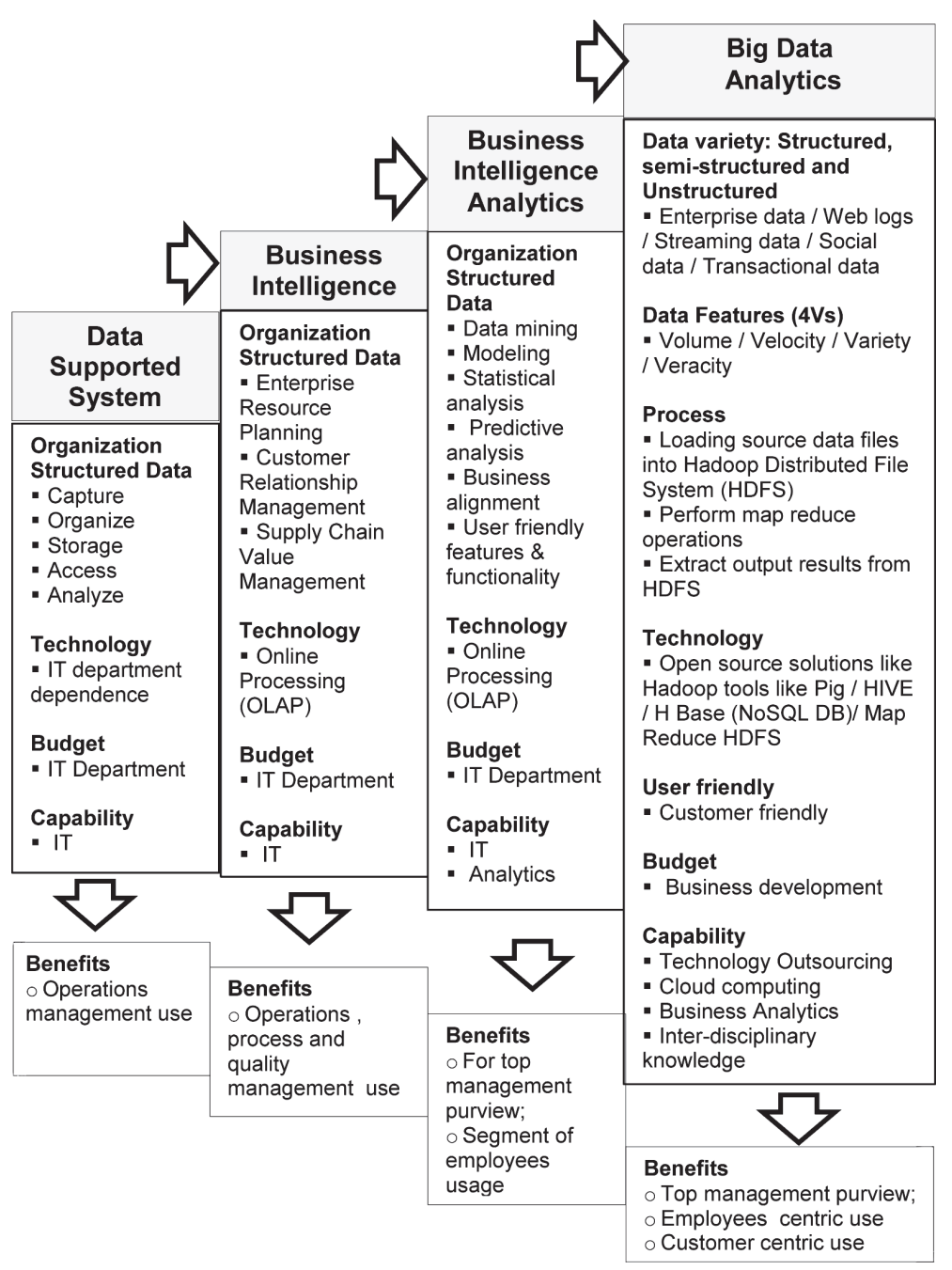

Fig. 1. Migratory framework towards big data analytics.

and development, creativity and innovation strategies. Such matured organizations are deemed to embrace and adopt BDA culture and practices. As highlighted in Fig. 1, having evolved into a distinct work practice and culture, the necessity for an evaluation framework on BDA has become an imperative, in particular for assessing and asserting presence of big data elements.

A decade ago, Gartner described the challenge of big data in terms of 3 'V's - volume, velocity and variety [21|26], while IBM viewed it under four "V"s (4V) namely volume, velocity, variety, and veracity [22]; see Fig. 2. In depicting big data talent analytics phenomena the Chartered Institute of Personal and Development (CIPD) also mooted $4 \mathrm{Vs}$ but differently entailing volume, velocity, variety and value dimensions [10]. Reckoning the significance and relevance of all the 'V's, this paper provides a consolidated Five V
Big Data Model Framework, as shown in Fig. 2. This framework is used for assessing the features and characteristics of big data phenomenon embedded in the ICT salary profile compilation initiative. The framework is also used for identifying the gaps that need to be rectified in realizing a full-fledged BDA in the near future.

Volume simply depicts the amount of data, which is continuously growing at an unprecedented rate [3]10, [22]. There is no distinct criterion or cut-off value in terms of petabytes and zetabytes for determining volume of a big data set [17]. High volume today will be higher volume tomorrow [22]. As highlighted earlier both the Jobstreet.com and PayScale.com not only have millions of records of job seekers in structured or matrix format, but also entail semi-structured and unstructured data. In the case of PayScale.com the geo- 


\begin{tabular}{|c||c|c|c|c|}
\hline \multicolumn{2}{|c|}{ Gartner Model (Laney, 2012) } & IBM, 2012 & CIPD, 2013 \\
\hline \hline $\begin{array}{c}\text { Volume } \\
\text { Retrospective } \\
\text { and real time } \\
\text { data }\end{array}$ & $\begin{array}{c}\text { Velocity } \\
\text { Speed, scale } \\
\text { and scope }\end{array}$ & $\begin{array}{c}\text { Variety } \\
\text { Range of } \\
\text { devices and } \\
\text { platforms }\end{array}$ & $\begin{array}{c}\text { Veracity } \\
\text { Data validity, } \\
\text { reliability and } \\
\text { authenticity }\end{array}$ & $\begin{array}{c}\text { Value } \\
\text { Integrate systems and } \\
\text { structures; } \\
\text { Build skills and } \\
\text { talents; } \\
\text { Encourage } \\
\text { collaboration and } \\
\text { connectivity }\end{array}$ \\
& & & \\
& &
\end{tabular}

Fig. 2. Integrated five V big data dimensions.

graphical coverage is not only regional but also global characterizing demographic diversity. The volume and data processing complexity is poised to increase many folds when data are sourced online and results are disseminated in real time. Nonetheless, the real challenge is not the technical or statistical capabilities or processes but it is the administrative and institutional arrangements to get access to such data.

Variety of data entails the complexity of data types and data sources [3]10[22]. In typical BDA activity the data comes not only in the structured form in the form of rectangular array or matrix format but also in the form of non-traditional particularly, semi-structured data from log files and click streams or unstructured text from comments and social media streams [9]10]. Such non-traditional data are residing in sensors, smart devises and social technology tools and infrastructure, both within and outside organizations like Linked-in that connects professionals globally. When external sources are linked with existing system data, variety and volume tend to increase in scope, coverage and content. When organization extracts untapped value from such data sources enormous knowledge convertible into intelligence and benefits can be realized [13]. Like in any online system, Jobstreet.com too are endowed with data in the form of text, web, tweets, audio, video, click streams and log files that yet to be explored.

Velocity is indeed depicts the data in motion, in particularly the rate at which data is created, processed, analyzed and disseminated [3]1022]. With technological advancements the latency speed, that is, the lag between data is created and being converted into meaningful information or knowledge is becoming shorter [22]. Jobstreet.com and PayScale.com have institutionalized online schemes for updating job registrants and job provision profiles, which yet to be explored to increase latency speed and report frequency; current arrangement is to produce annual report.
Veracity dimensions deals with validity and reliability aspects in data compilation [22[30]. Data quality and statistical integrity have been an age old concern in any measurement procedure and quantitative analysis [3 12/40] and BDA is not an exception. Issues of concerns in BDA authentication include exactitude, genuineness, originality, legitimacy, legality, rightfulness, dependability, authoritativeness, credibility, factualness, trustworthiness, historicity and bona fides. Lack of data veracity bound to have far reaching negative implications on data analyses including predictive exercises. In the current ICT salary compilation arrangement Jobstreet.com ensures data quality before supplying the data to the industry association. As a data user the industry association on its part also undertakes basic equivalence, stability and consistency checks that any typical statistical procedure demands [16]. However, data veracity tasks will be more challenging when internal and external databases are linked and integrated as typically envisaged in BDA [16]. However, literature review has revealed that anticipated challenges include validating structured and unstructured data, data storage and executing map reduce process using Hadoop technology and complex Pig and Hive programmes [5]. Besides functional testing, non-functional validation such as harmonizing differences in technological standards and settings, interoperability mechanisms, process scalability elements, work culture and processes, and institutional rules and regulations as well as conformance to service level agreement (SLA) warrant due attention.

Value deals with analytics that purposed to close the gap between data and business needs [6 10 [22, [38]. This requires understanding and mitigating obstacles in systems and structures in support of data and evidence driven approach [8]; developing the skills, smarts and talent pools; and encouraging internal collaboration and connectedness among departments with the idea of data and information as a key part of transformational tool kit [10 30]. In the current on-going 
ICT salary compilation exercise it may not entail the element of on-the-fly-decisions [9] but fostered and nurtured cooperation, collaboration, trust and confidence between the online service providers and the industry association. Currently, the report serves as a source document for remuneration adjustments, career structuring and policy advocacy. Indeed, such alliance is critical for any future endeavour in enhancing business relevance, improving operations, performance and innovation.

\section{Merits of collaboration between PIKOM and Jobstreet.com leading to official statistics}

The on-going collaboration between the industry association and online job service providers has brought about out a number of distinct features and merits. Firstly, the collaboration fostered a good working relationship, mutual trust and confidence between the online job service providers and industry association. This relationship model has demonstrated that through appropriate working arrangement, process and mechanism private sector data can be leveraged on generating not only business relevance numbers but also public policy relevant statistics as highlighted in the foregoing paragraphs. Secondly, the research collaboration has expanded the role of PIKOM beyond its traditional routines, which entail looking after industry growth and welfare of the members [29]. PIKOM uses the salary data for policy advocacy and intervention exercise whenever the mainstream Government agencies approach industry associations to provide issues and challenges plaguing the ICT industry. Thirdly, as a consequence of constant policy advocacy and intervention role the mainstream agencies have accorded recognition to various statistics by the industry association, without doubting its methodological integrity, validity and reliability [29]. Fourth, the ICT salary profile data published by PIKOM annually has gained equivalently "official statistics" status as endorsed by Digital Economy Satellite Account (DESA) working group, in which the Department of Statistics is also a member. Fifth, the inclusion of ICT data as an integral data for the DESA system enhances the national scope and coverage of official statistics, particularly under ICT data domain.

Sixth, and most importantly, the ICT salary profile data complemented the gaps in the national household income data that are periodically published by the national statistical agency. Specifically, being a sam- ple survey, the National Household Income Survey is able to provide valid and reliable as well as meaningfully consistent data at one digit level as per depiction in the Malaysian Standard Occupation Classifications 1998 (MASCO 1998). In other words, due to sampling limitations and fluctuations it will not be tenable and meaningful for compiling any data at three digit occupation level. But, at the one digit occupation level the income data under managerial and professional groups lumps up all kinds of professional jobs such as doctors, lawyers, engineers, legislators, accountants et cetera, including all ICT professionals especially those who have attained tertiary qualifications [35]. As highlighted in Table 3, the job market outlook study that PIKOM undertakes with online job service providers able to provide average income data earned by ICT professionals by type of job functions.

\section{Statistical integrity challenge}

The compilation of salary profile of ICT professionals is considered a market and business driven initiative where cost effective statistical production is of paramount concern. Typically private sectors do not spend huge amount of money for statistical collection activities especially involving primary survey approach that requires proper sampling and estimation procedures [27]. Nonetheless, private sectors are also in dire need of not only timely statistics but also valid and reliable numbers that can help to project future businesses. On the other hand in the case of official statistics production statistical integrity gauged in terms of quality, validity and reliability warrant due attention and always accorded top priority in any official statistics compilation activity [7/37/45]. As such, the national statistical offices or Government ministries that are routinely involved in the production and dissemination of various statistics implicitly assumes the role of quality function as per aspirations stipulated in the Principle 2 of Fundamental Principles of Official Statistics of UNSD [1941]. Specifically, "to retain trust in official statistics, the statistical agencies need to decide according to strictly professional considerations, including scientific principles and professional ethics, on the methods and procedures for the collection, processing, storage and presentation of statistical data". Thus, premising upon these tenets the statistical endeavour undertaken jointly by the industry association and the online job service providers will not be accorded any exception to the statistical demands de- 
picted in the Principle 2 of Fundamental Principles of Official Statistics of UNSD.

If that is so, then the question is how and who can ascertain the quality, validity, reliability and statistical integrity that are critical to safeguard the professionalism and standards of the practice. This is imperative in order to ensure accuracy and consistency across geography and over time; to guarantee statistics that are free from political interference, biasness and skewed interpretation; and towards quality management inclusive of the sound application of methodology to achieve the desired quality [7]19|39|41]. Response to these questions and challenges seems to suggest that the role, the governance process and the functions of national statistical office needs to be broadened [36]. Their role is not only to confine to the official statistics production and dissemination but also need their proactive involvement in assessing and endorsing the conformity and admission of private sector statistics as official statistics, wherever applicable. This process will help in expanding the scope and coverage of official statistics, particularly when many enterprises are turning big data into valuable information of uncovering inherent business, market, trade, investment and policy trends.

\section{Conclusion}

Converting private sector data into official statistics may not be that easy. Despite institutional challenges in creating official statistics the big data exercise is also facing at least two other major challenges at its current infancy stage. First, advanced and predictive analytical skills demand inter-disciplinary technical competencies and knowledge such as programming, cloud computing, mobility and social computing, operational research and business knowledge for getting the most value from BDA activities especially projecting anticipated changes using historical and current data [22]. Secondly, technologically designing an integrated business intelligence and big data platform can be a logistical and administrative nightmare especially involving external databases and more so ensuring data security, safety and interoperability elements [20]. Nonetheless, BDA is achievable through pragmatic and incremental implementation through establishing supportive working relationships between the service providers and industry associations. Essentially, this process requires identifying business and public policy requirements, tailoring the infrastructure, identifying the data sources and instituting analytics capability [10/17/30]. In addition, for generating private sector driven official statistics support of official statistical community is imperative. As such, collaboration with official statistical members and private sector deem to be the growing trend in the near future.

\section{References}

[1] Aberdeen Group (2013). Ever Harder and Faster: Managing the New Demands of Data Integration. Analyst insight by Aberdeen Group.

[2] J. Bersin, K. O'Leonard and W. Wang-Audia, High-impact talent analytics: Building a world-class HR measurement and analytics function, Bersin by Deloitte, October 2013.

[3] J. Bersin, Big Data in Human Resources: Talent Analytics Comes of Age. (http://www.forbes.com/), 2013.

[4] J. Bersin, Big Data in HR: building a competitive talent analytics function - four stages of maturity [online], 2012. Oakland, CA: Bersin by Deloitte: Available at http://www.Bersin. com/Practice/Detail.aspx ? docid $=15430 \&$ mode $=$ search \&p= Human-Resources.

[5] J. Bertolucci, Hadoop: From Experiment To Leading Big Data Platform, "Information Week", 2013. Retrieved on 14 November 2013.

[6] M. Beyer, Gartner Says Solving 'Big Data' Challenge Involves More Than Just Managing Volumes of Data, Gartner, 2011.

[7] L. Biggeri, Integrity - A Pre-requisite of Independence and Credibility of Official Statistics, Statistical Journal of the United Nations Economic Commission for Europe 21(3-4) (2004), 199-205. IOS Press.

[8] C. Boja, A. Pocovnicu and L. Bătăgan, Distributed Parallel Architecture for Big Data, Informatica Economica 16(2) (2012), 116-127.

[9] CDW, Business Intelligence Shows its Smarts. White paper published at CDW.com/businessintelligence, (2013).

[10] CIPD, (2013). Talent analytics and big data - The challenge for HR. Chartered Institute of Personal and Development (CIPD)/Oracle Research Report.

[11] D. Leinweber, Big Data Gets Bigger: Now Google Trends Can Predict The Market. Forbes. Retrieved August 9, 2013.

[12] M. Ehling and T. Korner, eds, Handbook on Data Quality Assessment Methods and Tools. Eurostat. European Commission, 2007.

[13] E. Kvochko, Four Ways to talk About Big Data (Information Communication Technologies for Development Series, worldbank.org. Retrieved 2012-05-30, 2012.

[14] B. Evelson, Want to know what Forrester's lead data analysts are thinking about BI and the data domain? 2010.

[15] Forbes (2008). Turning Classifieds Into Cash. Forbes 200801-18, retrieved 2013-10-28.

[16] M. Gudipati, S. Rao, N.D. Mohan and N.K. Gajja, Big Data: Testing Approach to Overcome Quality challenges, Infosys Labs Briefings 11(1) (2013).

[17] IBM (2013), IBM What is big data? - Bringing big data to the enterprise. www.ibm.com, retrieved 2013-08-26.

[18] L.I. Iezzoni, Assessing Quality Using Administrative Data. Annals of Internal Medicine. Harvard Medical School, Harvard University, Boston, Massachusetts, 1997.

[19] ISI (1986). Declaration of Professional Ethics for Statisticians. International Statistical Review 227-247. 
[20] P.J. Jamack, Big data business intelligence analytics, 2012. www.ibm.com/developerworks/ ibm/trademarks/.

[21] D. Laney, The Importance of 'Big Data': A Definition, Gartner, retrieved 21 June 2012.

[22] S. Lavlle, M. Hopkins, E. Lesser, R. Shockley and N. Kruschwitz, Analytics: The new path to value: How the smartest organizations are embedding analytics to transform insights into action, IBM Global Business Services, 2011.

[23] H.P. Luhn, A Business Intelligence System, IBM Journal 2(4) (1958), 314. doi:10.1147/rd.24.0314

[24] J. Manyika, M. Chui, B. Brown, J. Bughin, R. Dobbs, C. Roxburgh and A.H.M. Byers, Big Data: The next frontier for innovation, competition, and productivity, McKinsey Global Institute, 2011.

[25] M. Hilbert, Big Data for Development: From Informationto Knowledge Societies, SSRN Scholarly Paper No. ID 2205145. Rochester, NY: Social Science Research Network, 2013. http://papers.ssrn.com/abstract=2205145.

[26] A. McAfee and E. Brynjolfsson, Big Data. The management revolution, Harvard Business Review 90(10) (2012), 60-68.

[27] M.N. Murthy, Sampling Theory and Methods, Statistical Publishing Society, 1977, pp. 95-99.

[28] R.S. Nandyal, CMMI. Framework of Constellations for Building World Class IT Organizations, Nandyal, R.S. Tata McGraw-Hill publication, 2011.

[29] K.Y. Ong and R. Ramachandran, PIKOM moving up in the value chain: Advocacy to value creation, Published in "ICT Strategic Review 2012/13: The Digital Opportunity, PIKOM, 2012.

[30] Oracle and FSN (2012). Mastering Big Data: CFO Strategies to Transform Insight into Opportunity, December 2012.

[31] PIKOM (2013). Addressing talent needs of the Economic Transformation Programme by TalentCorp Malaysia. Published in "ICT Strategic Review 2013/14: The Digital Opportunity". PIKOM.

[32] PIKOM (2014). ICT Job Market Outlook in Malaysia, Annual series published by PIKOM.

[33] D.J. Power, A Brief History of Decision Support Systems, (2007). version 4.0. DSS Resources.COM.
[34] L. Raine and B. Wellman, Networked. The New Social Operating System, Cambridge: MIT Press, 2012.

35] R. Ramachandran and Vigneswarer, Statistical Compilation of ICT Sector in Malaysia, Published by Orbicom, the International Network of UNESCO Chairs in Communication 2011.

[36] R. Ramachandran, Measuring Knowledge Development and Developing Official Statistics for the Information Age, International Statistical Review 71(1) (2003), 83-107.

[37] R. Ramachandran, Measuring Information Development in the New Millennium, Thesis submitted in fulfilment of the requirement for the Degree of Master of Philosophy, Multimedia University, Cyberjaya, Malaysia, 2008.

[38] C. Snijders, U. Matzat and U.-D. Reips, 'Big Data': Big gaps of knowledge in the field of Internet, International Journal of Internet Science 7 (2012), 1-5. http://www.ijis.net/ijis7_1/ ijis7_1_editorial.html.

[39] M.L. Straf, Statistics in next Generation, Journal of the American Statistical Association 98 (2003), 1-6.

[40] S.M. Tam and F. Clarke, Big Data, Official Statistics and Some Initiatives by the Australian Bureau of Statistics. IAOS 2014 Conference on Official Statistics Meeting the demands of a changing world. Da Nang, Viet Nam, 8-10 October 2014.

[41] UNSD (2006). Fundamental Principles of Official Statistics.

[42] C. Vaccari, An experience of international collaboration on Big Data for Official Statistics. IAOS 2014 Conference on Official Statistics Meeting the demands of a changing world. Da Nang, Viet Nam, 8-10 October 2014.

[43] A. Wahab, Essence of ICT Roadmap 2012 for Innovation Driven Growth. ICT Strategic Review 2012/2013: Innovation for Digital Opportunities, 2011. PIKOM Publication ISSN No. 21802548.

[44] J. Webster, MapReduce: Simplified Data Processing on Large Clusters, Search Storage, 2004. Retrieved on 25 March 2013.

[45] A.W. Wyckoff, OECD Efforts to Address the Measurement and Policy Challenges posed by the Information Society, Paper presented at IAOS Satellite Meeting on Statistics for the Information Society, 30-31 August 2001, Tokyo Japan. 